\title{
Dichotic Listening Tests of Functional Brain Asymmetry Predict Response to Fluoxetine in Depressed Women and Men
}

\author{
Gerard E Bruder*,1,2, Jonathan W Stewart ${ }^{1,3}$, Patrick J McGrath ${ }^{1,3}$, Deborah Deliyannides ${ }^{3}$ and \\ Frederic M Quitkin ${ }^{1,3}$ \\ 'Department of Psychiatry, Columbia University College of Physicians and Surgeons, New York, NY, USA; '²Department of Biopsychology, New \\ York State Psychiatric Institute, New York, NY, USA; ${ }^{3}$ Depression Evaluation Service, New York State Psychiatric Institute, New York, NY, USA
}

\begin{abstract}
Patients having a depressive disorder vary widely in their therapeutic responsiveness to a selective serotonin reuptake inhibitor (SSRI), but there are no clinical predictors of treatment outcome. Studies using dichotic listening, electrophysiologic and neuroimaging measures suggest that pretreatment differences among depressed patients in functional brain asymmetry are related to responsiveness to antidepressants. Two new studies replicate differences in dichotic listening asymmetry between fluoxetine responders and nonresponders, and demonstrate the importance of gender in this context. Right-handed outpatients who met DSM-IV criteria for major depression, dysthymia, or depression not otherwise specified were tested on dichotic fused-words and complex tones tests before completing 12 weeks of fluoxetine treatment. Perceptual asymmetry (PA) scores were compared for 75 patients (38 women) who responded to treatment and 39 patients ( 14 women) who were nonresponders. Normative data were also obtained for 101 healthy adults (6I women). Patients who responded to fluoxetine differed from nonresponders and healthy adults in favoring left- over righthemisphere processing of dichotic stimuli, and this difference was dependent on gender and test. Heightened left-hemisphere advantage for dichotic words in responders was present among women but not men, whereas reduced right-hemisphere advantage for dichotic tones in responders was present among men but not women. Pretreatment PA was also predictive of change in depression severity following treatment. Responder vs nonresponder differences for verbal dichotic listening in women and nonverbal dichotic listening in men are discussed in terms of differences in cognitive function, hemispheric organization, and neurotransmitter function. Neuropsychopharmacology (2004) 29, I752- I76I, advance online publication, 7 July 2004; doi: I 0.1038/sj.npp. 13005 I 9
\end{abstract}

Keywords: depression; SSRI; fluoxetine; treatment response; laterality; dichotic listening

\section{INTRODUCTION}

Selective serotonin reuptake inhibitors (SSRIs) are effective in treating less than two-thirds of patients having a depressive disorder, but there are no clinical predictors of whether a patient will benefit from an SSRI antidepressant. There is, however, growing evidence that individual differences among depressed patients on genetic (Zanardi et al, 2001), biochemical (Figueras et al, 1999), neuroimaging (Buchsbaum et al, 1997; Mayberg et al, 1997; Brody et al, 1999; Saxena et al, 2003; Davidson et al, 2003), electrophysiologic (Bruder et al, 2001; Cook and Leuchter, 2001; Pizzagalli et al 2001; Kalayam and Alexopoulos, 2003;

* Correspondence: Dr G Bruder, Department of Biopsychology, New York State Psychiatric Institute, I05I Riverside Drive, New York, NY 10032, USA, Tel: + I 212543 5468, Fax: + I 2125436540 ,

E-mail: bruderg@pi.cpmc.columbia.edu

Received 24 February 2004; revised 28 May 2004; accepted I June 2004

Online publication: 4 June 2004 at http://www.acnp.org/citations/ Npp060304040078/default.pdf
Mulert et al, 2002), and neurocognitive (Dunkin et al, 2000) measures are associated with therapeutic response to an SSRI or other antidepressants.

Studies using dichotic listening, electrophysiologic (EEG) and neuroimaging measures indicate that asymmetric activation of right-left brain regions may be related to responsiveness to antidepressants (Bruder, 2003; Davidson et al, 2003; Stewart et al, 1999). In dichotic listening tests, different stimuli (eg words or tones) are simultaneously presented to the left and right ears, and differences in performance between ears provide a measure of perceptual asymmetry (PA). Ear advantages on dichotic tests are thought to represent the advantage of the contralateral hemisphere for processing verbal or tonal stimuli. The Fused Rhymed Words Test yields a right-ear advantage in healthy adults having left-hemisphere dominance for language processing (Wexler and Halwes, 1983; Zatorre, 1989). In contrast, the Complex Tone Test, which provides a measure of right-hemisphere dominance for pitch discrimination, yields a left-ear advantage in healthy adults (Sidtis, 1981). While studies have generally found reduced 
or absent right-hemisphere advantage in depressed patients for nonverbal dichotic tests, findings for verbal tests have been inconsistent (see Bruder, 1988 for a review), and some studies have found a normal left-hemisphere advantage in depressed patients for perceiving dichotic consonant-vowel syllables (Hugdahl et al, 2003). Inconsistent findings may reflect not only methodological differences, for example, use of different dichotic tests, but also the clinical heterogeneity of depressive disorders. It has been suggested that differences among depressed patients on dichotic listening tests may help to define pathologically distinct subtypes (Wexler et al, 1989). Differences in dichotic listening PA have been found between diagnostic subtypes of depression (Bruder et al, 1989) and between patients who respond to a tricyclic antidepressant and those who do not (Bruder et al, 1990).

In a prior study of the SSRI fluoxetine (Bruder et al, 1996), unmedicated depressed patients at two clinical centers who subsequently responded to fluoxetine had greater left-hemisphere advantage for dichotic fused words and less right-hemisphere advantage for complex tones when compared to treatment nonresponders. There was no change in PA following treatment, which suggests that the difference between fluoxetine responders and nonresponders represents a stable, state-independent characteristic. These results supported the hypothesis that a characteristic PA favoring left- over right-hemispheric activation during dichotic listening is associated with favorable response to fluoxetine, whereas the opposite hemispheric asymmetry predicts poor response.

This report presents findings of two additional studies that replicate differences in dichotic listening asymmetry between fluoxetine responders and nonresponders, which is of importance given the lack of findings replicating predictors of treatment response (Joyce and Paykel, 1989; Sotsky et al, 1991). One study included a 6-week placebo lead-in period, providing some control over nonspecific placebo response. Moreover, the relatively large sample of patients in these studies allowed us to examine the role of gender in this context. The greater prevalence of depression among women (Weissman et al, 1984) and gender differences in cognitive function and hemispheric organization point to the importance of examining this variable (Heller, 1993). The tendency for women to perform better on verbal tasks and men to perform better on spatial tasks appears to be related to differences in hemispheric specialization (Hiscock et al, 1995). Studies have found evidence that the superiority of women for verbal processing results from their having bilateral activation of frontal and temporal lobe regions involved in language processing, whereas men are more left lateralized for verbal processing (McGlone, 1980; Bryden, 1988; Shaywitz et al, 1995; Kimura, 1999; Kansaku et al, 2000). Gur et al (2000) found that men also show more right-lateralized activation of inferior parietal and temporal lobe regions during a visuospatial task and tend to perform better when compared to women. Gender differences have also been reported for serotonergic function and it has been suggested that these differences are related to the development of gender-related disorders such as depression (Arato et al, 1991b; Steiner et al, 1997). Our preliminary findings suggested that pretreatment differences between fluoxetine responders and nonresponders on dichotic fused words and EEG asymmetry measures are more evident among depressed women than men (Bruder et al, 2001). We report below the findings for larger samples from two studies that confirm the importance of gender in this context.

\section{METHODS}

\section{Patients}

The patients were right-handed depressed outpatients between the ages of 18 and 65 who were attending a university-affiliated Depression Evaluation Service at New York State Psychiatric Institute. Patients were excluded for any of the following reasons: serious suicide risk, substance abuse disorders (including alcohol abuse) within the last 6 months, psychotic disorders, antisocial personality disorder, seizure disorder, organic mental disorder, history of head trauma, or other neurological disorder. Patients were also excluded if they had a hearing loss greater than $30 \mathrm{~dB}$ in either ear at 500,1000 , or $2000 \mathrm{~Hz}$ or if they had an ear difference greater than $10 \mathrm{~dB}$. All participants signed informed consent forms before participating in the study.

The diagnostic assessment and treatment of patients were carried out by research psychiatrists in the Depression Evaluation Service. The patients were participants in two treatment studies, for which preliminary findings were presented for less than half of the samples in this report (Bruder et al, 2001). In Study 1, 65 patients who met DSMIV criteria for major depressive disorder (MDD) were tested during a 7-10 days single-blind placebo period and then completed 12 weeks of fluoxetine treatment. This was an open clinical trial and patients were therefore aware of receiving active medication during the 12-week period. Patients received $10 \mathrm{mg}$ of fluoxetine during week $1,20 \mathrm{mg}$ during weeks 2-4, and $40 \mathrm{mg}$ during weeks 5-8, and if there was still no response, a further increase to $60 \mathrm{mg}$ was permitted during weeks 9-12. In Study 2, 64 patients were tested before receiving placebo for 6 weeks single-blind or during the first week of placebo. Of these patients, 15 responded to placebo (see definition below). Only patients who were placebo nonresponders received 12 weeks of treatment with fluoxetine. Patients began fluoxetine treatment at $20 \mathrm{mg}$, and the dose was increased biweekly up to a maximum of $80 \mathrm{mg}$ depending on clinical need and tolerance. The 49 patients who completed the 12 weeks of fluoxetine treatment were more heterogeneous in their diagnoses than the patients in Study 1, with eight meeting DSM-IV criteria for MDD, 23 for dysthymia, seven for both of these disorders (double depression), 11 for depression not otherwise specified, and one for bipolar disorder. In both studies, an independent evaluator, blind to the patient's dichotic listening data, rated each patient at the end of 12 weeks of treatment using the Clinical Global Impression Improvement (CGI-I) scale. Patients who had a CGI-I rating of 'much improved' or 'very much improved' were considered to be responders and all other patients were considered as nonresponders.

Table 1 gives the characteristics of the 75 patients who were classified as fluoxetine responders and the 39 patients who were nonresponders. There was approximately equal numbers of women and men in the responder group, but a 
Table I Characteristics of Treatment Responders and Nonresponders

\begin{tabular}{|c|c|c|c|c|}
\hline & \multicolumn{2}{|c|}{ Responders } & \multicolumn{2}{|c|}{ Nonresponders } \\
\hline & Women & Men & Women & Men \\
\hline$n$ & 38 & 37 & 14 & 25 \\
\hline \multicolumn{5}{|c|}{ Age (years) } \\
\hline M & 36.0 & 41.2 & 36.1 & 38.4 \\
\hline SD & 12.4 & 11.3 & 14.3 & 11.1 \\
\hline \multicolumn{5}{|c|}{ Education (years) } \\
\hline M & $15.4^{\mathrm{a}}$ & $15.8^{b}$ & 14.8 & 15.2 \\
\hline SD & 2.3 & 2.5 & 2.8 & 2.4 \\
\hline \multicolumn{5}{|c|}{ Handedness (LQ) } \\
\hline M & 83.0 & 80.6 & 94.3 & 92.5 \\
\hline SD & 19.4 & 18.4 & 9.5 & 10.7 \\
\hline \multicolumn{5}{|c|}{ Major depressive disorder ${ }^{c}$} \\
\hline$\%$ & 84.2 & 59.4 & 85.7 & 52.0 \\
\hline \multicolumn{5}{|c|}{ Anxiety disorder ${ }^{d}$} \\
\hline$\%$ & 13.2 & 8.1 & 35.7 & 24.0 \\
\hline \multicolumn{5}{|c|}{ Pretreatment HAM-D-2I } \\
\hline M & 15.8 & 14.8 & 16.0 & 14.7 \\
\hline SD & 4.4 & 5.7 & 5.4 & 6.2 \\
\hline \multicolumn{5}{|c|}{ Post-treatment HAM-D-2 $1^{e}$} \\
\hline M & 4.4 & 3.8 & 15.0 & $13.0^{f}$ \\
\hline SD & 2.8 & 3.1 & 4.9 & 5.9 \\
\hline \multicolumn{5}{|c|}{$\begin{array}{l}{ }^{a} n=37 . \\
b_{n}=35 . \\
{ }^{c} M e n \text { differ significantly from women, } \chi^{2}=10.54, d f=1, p<0.01 . \\
\text { d Responders differ significantly from nonresponders, } \chi^{2}=5.67, \mathrm{df}=1, p<0.05 . \\
\text { e Responders differ significantly from nonresponders, } F=144.43, \mathrm{df}=1,109, \\
p<0.001 .\end{array}$} \\
\hline
\end{tabular}

somewhat smaller proportion of nonresponders were women, and therefore gender was included as a variable in statistical analyses. An analysis of variance (ANOVA) with treatment response as one variable and gender as a second variable did not reveal a significant difference among groups in age or education. All patients were right handed, as indicated by their positive laterality quotient (LQ) on the Edinburgh Handedness Inventory (Oldfield, 1971). The percentage of patients meeting criteria for MDD did not differ between responders and nonresponders, but fewer men in each group had an MDD when compared to women $\left(\chi^{2}=10.54, \mathrm{df}=1, p<0.01\right)$. Nonresponders differed from responders in having a higher percentage with comorbid anxiety disorders, that is, primarily social phobia or panic disorders $\left(\chi^{2}=5.67, \mathrm{df}=1, p<0.05\right)$. Although too few patients had anxiety disorders to include this as a variable, analyses of the dichotic listening data were repeated after excluding patients having a comorbid anxiety disorder, and the results were essentially the same as reported below for the full samples. There was no difference among groups in pretreatment severity of depressive symptoms, as measured by the Hamilton Rating Scale $\left(\mathrm{HAM}-\mathrm{D}_{21}\right)$. Following treatment, both women and men who responded to treatment had markedly lower HAM- $\mathrm{D}_{21}$ scores than nonresponders $(\mathrm{F}=144.43, \mathrm{df}=1,109$, $p<0.001)$.

\section{Healthy Adults}

Normative data for the Fused Rhymed Words Test and the Complex Tone Test were obtained for 101 right-handed healthy adults (61 women, 40 men). These healthy adults were screened to exclude those having psychopathology, substance abuse, history of head trauma, neurological disorder, hearing loss greater than $30 \mathrm{~dB}$ in either ear at 500,1000 , or $2000 \mathrm{~Hz}$, or an ear difference greater than $10 \mathrm{~dB}$. The mean age of the healthy women was 30.0 $(\mathrm{SD}=8.8)$ and that of the men was $31.3(\mathrm{SD}=7.6)$. Although their mean age is somewhat younger than for the patient groups, age was not significantly related to their PA scores on either the fused-words $(r=-0.16, \mathrm{NS})$ or complex tones ( $r=-0.03$, NS) tests, nor was education level significantly associated with PA scores for these tests.

\section{Dichotic Listening Tests}

Patients were unmedicated a minimum of 7 days before testing, although most patients were drug free for a considerably longer period or were not previously treated with an antidepressant. No patient was tested within 6 weeks of receiving fluoxetine or 2 weeks of receiving other antidepressants. All patients were tested on the dichotic fused-words and complex tones tests described below, with the order of the tests counterbalanced across patients.

The Fused Rhymed Words Test (Wexler and Halwes, 1983) consists of 15 different single-syllable word pairs in which each member of every pair differs from the other only in the initial consonant (eg coat, goat). All words begin with one of six stop consonants (b, d, p, t, g, k) and are natural speech spoken by a male voice. When presented dichotically, the members of each pair fuse into a single percept. Participants indicate what word they heard by marking a line through it on a prepared answer sheet that has four possible responses, both members of the dichotic pair and two other words differing from the dichotic stimuli only in the initial consonant. Following practice trials, each participant received four 30-item blocks for a total of 120 trials. Orientation of headphones was reversed after the first and third quarters to control for channel differences and ear of presentation. The words were presented via a matched pair of TDH- 49 headphones at a comfortable level of $75 \mathrm{~dB}$ sound pressure level (SPL).

The Complex Tone Test (Sidtis, 1981) requires participants to compare the pitch of a binaural complex tone with the pitches of a dichotic pair of complex tones presented $1 \mathrm{~s}$ earlier. Subjects point to a response card labeled Yes when 
the probe tone is the same as either member of the previous dichotic pair or to a card labeled No when it differs from both. The complex tones are square waves with fundamental frequencies corresponding to eight notes in the octave between $\mathrm{C} 4$ and $\mathrm{C} 5$. After 16 binaural and 16 dichotic practice trails, participants were tested on four blocks of 28 trials in which half of the probe tones matched a member of the dichotic pair and half did not. Orientation of headphones was reversed after the first and third blocks. The tones were presented at $74 \mathrm{~dB}$ SPL.

\section{Statistical Analyses}

The number of correct responses in the fused-words and complex tones tests was computed for right- and left-ear presentations. These scores were used to compute a measure of PA for each task, where PA=100(Right Correct-Left Correct)/(Right Correct + Left Correct). A $2 \times 2 \times 2 \times 2$ ANOVA of PA scores included the betweensubject variables of Treatment Response (responder, nonresponder), Gender (women, men) and Treatment Study $(1,2)$, and one repeated-measure factor of Test (words, tones). Differences between responders and nonresponders on each test were examined with $t$-tests. Two additional ANOVA of PA scores were computed: (1) to control for possible effects of anxiety disorders, a 2 (Treatment Response) $\times 2$ (Gender) $\times 2$ (Test) ANOVA was computed including only the 67 fluoxetine responders and 28 nonresponders without an anxiety disorder; and (2) to assess placebo effects, this $2 \times 2 \times 2$ ANOVA compared the PA scores for 15 patients (four women) in Study 2 who responded to 6 weeks of placebo and 49 patients (14 women) who were placebo nonresponders.

In order to examine whether group differences in PA scores on the Complex Tone Test were due to differences in left-ear accuracy, right-ear accuracy, or both, absolute accuracy scores for tones presented to the left and right ears were analyzed using an ANOVA with between-subject variables of Group (responder, nonresponder, controls) and Gender (women, men), and the repeatedmeasure Ear (left, right). No analyses of accuracy data for the fused-words test were performed because the members of the dichotic pair fuse into a single percept and subjects are essentially $100 \%$ correct for reporting the word heard in either ear.

The potential value of PA scores on the dichotic tests for predicting therapeutic response to fluoxetine in women and men was examined using $\chi^{2}$-tests to compare the response rate of patients with PA scores above $v s$ below the mean score for healthy adults. Sensitivity, specificity, positive predictive value, and negative predictive value were computed separately for women and men. The predictive significance of the dichotic listening tests was also examined with logistic regression analyses, in which PA scores for the word and tone tests were included in a linear model predicting response to fluoxetine. After controlling for baseline ratings of symptom severity on the HAM- $\mathrm{D}_{21}$, correlations were computed to determine whether pretreatment PA scores were associated with changes in HAM- $D_{21}$ ratings after 12 weeks of fluoxetine treatment.

\section{RESULTS}

Figure 1 shows the PA scores for treatment responders and nonresponders in Study 1 and 2. The arrows show the mean left-hemisphere advantage for words (ie positive PA scores) and right-hemisphere advantage for tones (ie negative PA scores) for healthy adults (HA). The responders and nonresponders also showed the expected difference in PA for words and tones $(\mathrm{F}=146.90, \mathrm{df}=1,106, p<0.001)$. In both studies, responders had a larger left-hemisphere advantage for words and a smaller right-hemisphere advantage for tones when compared to nonresponders. The common direction of this group difference in asymmetry for words and tones was reflected in a main effect of Treatment Response $(\mathrm{F}=8.69, \mathrm{df}=1,106$, $p<0.005)$. The magnitude of the difference in PA between responders and nonresponders was essentially the same across studies, which is supported by the lack of a significant main effect or interaction involving the Study variable.

The difference in asymmetry between responders and nonresponders on each test was, however, dependent on gender, as indicated by a Treatment Response $\times$ Gender $\times$ Test interaction $(\mathrm{F}=10.72, \mathrm{df}=1,106, p=0.001)$. The nature of this interaction is illustrated in Figure 2, which shows the PA scores for responders and nonresponders plotted separately for women and men. The data in this figure were averaged across studies because the Treatment Response $\times$ Gender $\times$ Test interaction was equally evident in Study $1(\mathrm{~F}=5.54, \mathrm{df}=1,61, p<0.05)$ and Study 2 $(\mathrm{F}=5.17, \mathrm{df}=1,45, \quad p<0.05)$. On the words test, the tendency for responders to have a larger left-hemisphere advantage than nonresponders was evident for women but not for men. The mean left-hemisphere advantage for women who responded to fluoxetine was about three times as large as seen for nonresponders $(t=4.48, \mathrm{df}=50$, $p<0.001$ ), but there was no significant difference in the left-hemisphere advantage for words between male respon-

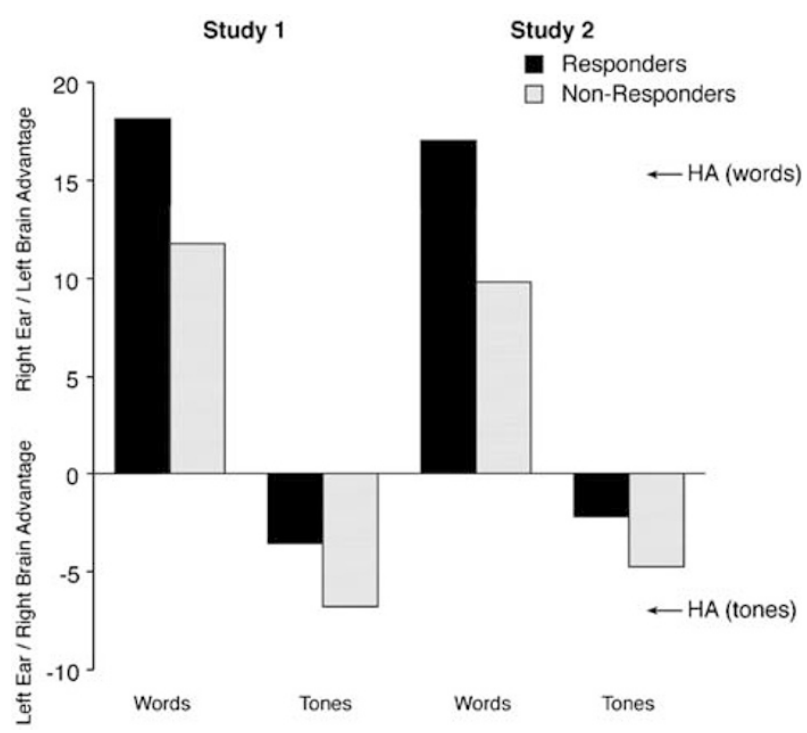

Figure I Mean PA scores on dichotic fused-words and complex tones tests for fluoxetine responders and nonresponders in two studies. PA score $=100(R-L) /(R+L)$, where $R=$ right-ear accuracy and $L=$ left-ear accuracy. $H A=$ mean PA scores for 101 healthy adults. 


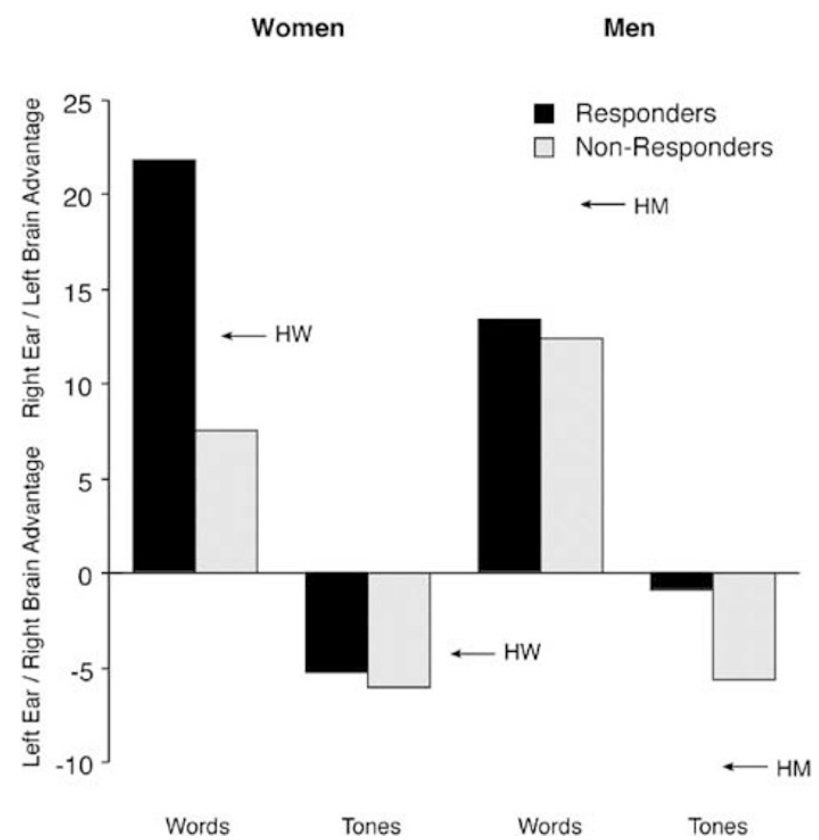

Figure 2 Mean PA scores on dichotic fused-words and complex tones tests for women and men fluoxetine responders and nonresponders averaged over studies. PA score $=100(R-L) /(R+L)$, where $R=$ right-ear accuracy and $L=$ left-ear accuracy. $H W=$ mean PA scores for 61 healthy women and $\mathrm{HM}=$ mean PA scores for 40 healthy men.

ders and nonresponders. Women who responded to fluoxetine also had significantly larger left-hemisphere advantage for words when compared to healthy women (arrow labeled HW in Figure 2; $t=3.16, \mathrm{df}=97, p<0.005$ ). Female nonresponders tended to have a smaller lefthemisphere advantage for words relative to healthy women, but this difference was not statistically significant, nor was there a significant difference in the left-hemisphere advantage for words between male responders or nonresponders and healthy men (arrow labeled HM in Figure 2). On the complex tones test, the tendency for responders to have a smaller right-hemisphere advantage than nonresponders was evident for men but not women. Men who responded to fluoxetine had significantly smaller righthemisphere advantage for tones when compared to either male nonresponders $(t=2.20, \mathrm{df}=60, p<0.05)$ or healthy men $(t=4.56, \mathrm{df}=75, p<0.001)$. In contrast, there was no significant difference in right-hemisphere advantage for tones between women responders and nonresponders or between these groups and healthy women; nor was there a significant difference in right-hemisphere advantage between male nonresponders and healthy men.

Absolute accuracy scores for perceiving complex tones in the left or right ear are given in Table 2 for responders, nonresponders, and healthy adults. An ANOVA of these accuracy scores revealed a significant Group $\times$ Gender $\times$ Ear interaction $(\mathrm{F}=5.39, \mathrm{df}=2,209, p=0.005) . \quad$ Men who responded to fluoxetine failed to show the significant left-ear (right-hemisphere) advantage seen for the other groups of men and women. These accuracy data also suggest that the reduced right-hemisphere advantage in male responders was due, at least in part, to their better right-ear (left-hemisphere) accuracy. There was a signifi-
Table 2 Percent Correct for Complex Tones in Left and Right Ear for Responders, Nonresponders, and Healthy Adults

\begin{tabular}{|c|c|c|c|c|c|c|}
\hline & \multicolumn{2}{|c|}{ Responders } & \multicolumn{2}{|c|}{ Nonresponders } & \multicolumn{2}{|c|}{ Healthy adults } \\
\hline & Women & Men & Women & Men & Women & Men \\
\hline$n$ & 38 & 37 & 14 & 25 & 61 & 40 \\
\hline \multicolumn{7}{|c|}{ Left ear } \\
\hline$M$ & $87.8^{\mathrm{a}}$ & 85.0 & $91.8^{\mathrm{b}}$ & $89.0^{c}$ & $90.4^{d}$ & $88.2^{\mathrm{e}}$ \\
\hline SD & 9.3 & 14.7 & 9.8 & 10.0 & 10.5 & 9.7 \\
\hline \multicolumn{7}{|c|}{ Right ear } \\
\hline$M$ & $80.0^{\mathrm{a}}$ & $83.1^{\mathrm{f}}$ & $82.4^{b}$ & $80.8^{\mathrm{c}, \mathrm{f}}$ & $83.2^{d}$ & $73.1^{e, f}$ \\
\hline SD & 15.1 & 13.7 & 15.2 & 17.2 & 13.8 & 18.7 \\
\hline \multicolumn{7}{|c|}{ 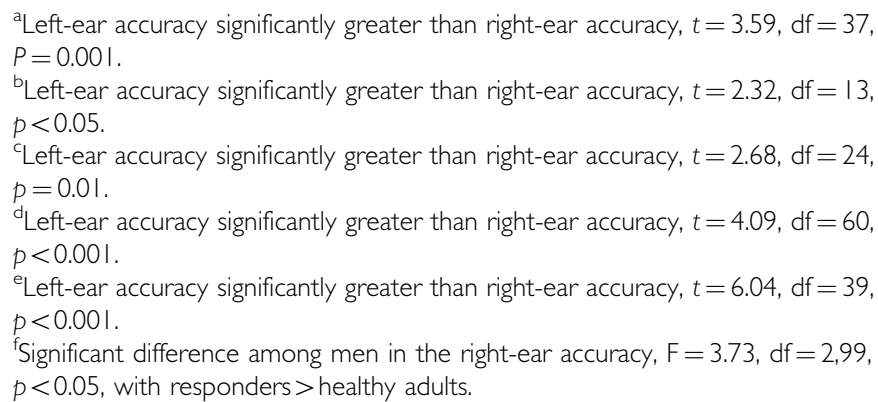 } \\
\hline
\end{tabular}

cant difference in right-ear accuracy among the male groups $(\mathrm{F}=3.73, \mathrm{df}=2,101, p<0.05)$, with male responders showing better performance compared to healthy men $(p<0.05)$, and nonresponders showing an intermediate accuracy level. In contrast, differences in left-ear accuracy among men, or differences in left- or right-ear accuracy among women, were not statistically significant.

When the PA data were reanalyzed including only fluoxetine responders and nonresponders without a comorbid anxiety disorder, the findings were essentially the same as reported above for the full sample. An ANOVA of the data for these patients yielded the same main effect of Treatment Response $(\mathrm{F}=13.08, \mathrm{df}=1,91, p<0.001)$ and a Treatment Response $\times$ Gender $\times$ Test interaction $(F=5.79$, $\mathrm{df}=1,91, p<0.05)$. These effects were not, however, evident in an analysis of the PA data for the 15 placebo responders and 49 placebo nonresponders in Study 2. An ANOVA of their data did not yield a significant main effect of Treatment Response $(\mathrm{F}=0.53, \mathrm{df}=1,60, p=0.47)$ or interactions involving gender. The left-hemisphere advantage for words was not different in placebo responders $(\mathrm{M}=8.95, \mathrm{SD}=17.24)$ and nonresponders $(\mathrm{M}=13.88$, $\mathrm{SD}=15.2$ ), nor was there a difference in the right-hemisphere advantage for tones between placebo responders $(\mathrm{M}=-3.20, \mathrm{SD}=6.39)$ and nonresponders $(\mathrm{M}=-3.34$, $\mathrm{SD}=9.38$ ). Thus, they showed no evidence of the difference in PA seen between fluoxetine responders and nonresponders.

Inspection of the distributions of PA scores on the fusedwords test for women who were fluoxetine responders or nonresponders (left portion of Figure 3) suggests its value 


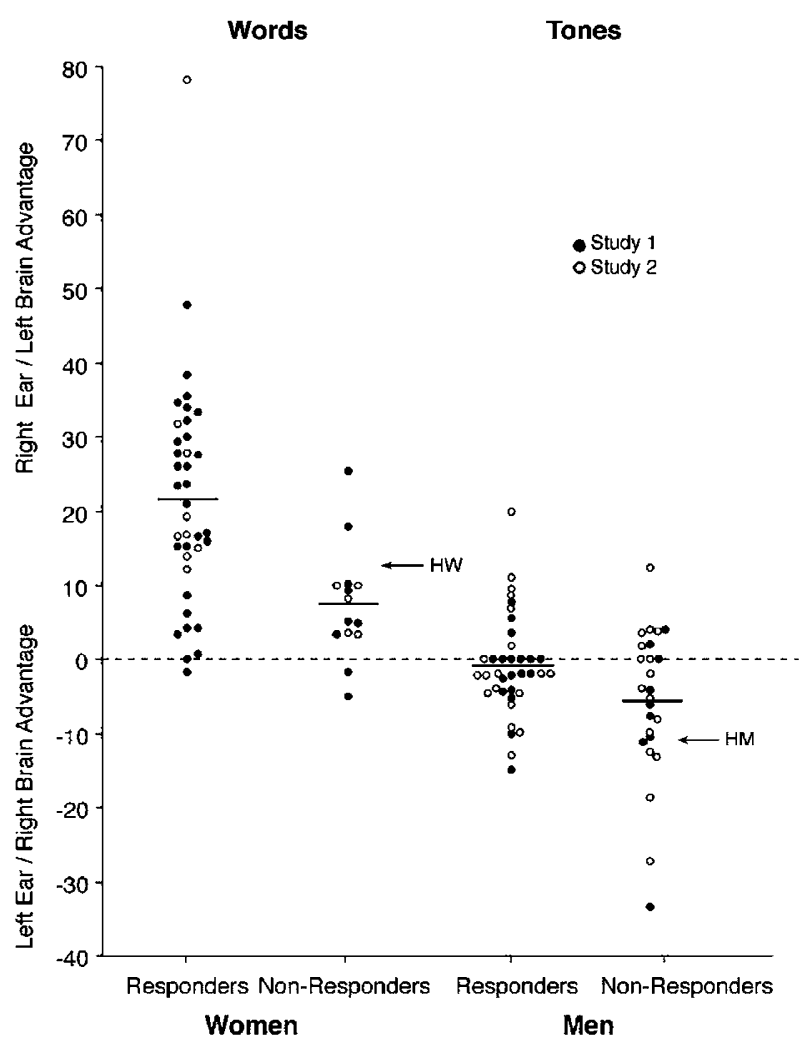

Figure 3 PA scores for individual women fluoxetine responders and nonresponders, and mean PA score for $6 I$ healthy women (HW) on the fused-words test (left portion of the figure); PA scores for individual men fluoxetine responders and nonresponders, and mean PA score for 40 healthy men (HM) on the complex tone test (right portion of the figure). Closed circles represent Study I and open circles Study 2.

for predicting outcome of treatment. This figure also illustrates the agreement of the PA data across Study 1 (solid circles) and Study 2 (open circles). As in the past (Bruder et al, 2001), we used the mean PA score for healthy women (arrow labeled HW in Figure 3) as a cutoff score for dividing patients into those with relatively large $v s$ small left-hemisphere advantage, and a comparison was made of their treatment response. Of the 32 women with a lefthemisphere advantage above the normal mean, 29 responded to fluoxetine (ie a $94 \%$ response rate), whereas only nine of 21 women with a left-hemisphere advantage less than normal responded to fluoxetine (ie a $43 \%$ response rate; $\left.\chi^{2}=16.30, \mathrm{df}=1, p<0.001\right)$. Using this cutoff score to predict fluoxetine response among women, the fused-words test had a relatively high sensitivity, specificity, and positive predictive value in both Study 1 and 2 (see Table 3). The negative predictive value was higher in Study 2 than in Study 1, which may stem from the longer placebo period in Study 2. Thus, the 6-week placebo lead-in might be expected to reduce the number of patients who are predicted to be fluoxetine nonresponders (ie PA score below normal mean), but who have a nonspecific, 'placebo' response during active treatment (see left portion of Figure 3).

Women with a left-hemisphere advantage for words above the normal mean had considerably greater response rate to fluoxetine than would be expected to occur on
Table 3 Indices Evaluating Predictions of Response Using Fused-Words Test for Women and Complex Tone Test for Men

\begin{tabular}{|c|c|c|}
\hline & Women - fused words & Men-complex tones \\
\hline \multicolumn{3}{|l|}{ Sensitivity $^{a}$} \\
\hline Study I & 72.4 & 94.4 \\
\hline Study 2 & 88.9 & 94.7 \\
\hline Total & 76.3 & 94.6 \\
\hline \multicolumn{3}{|l|}{ Specificity ${ }^{b}$} \\
\hline Study I & 77.8 & 22.2 \\
\hline Study 2 & 100 & 25.0 \\
\hline Total & 85.7 & 24.0 \\
\hline \multicolumn{3}{|c|}{ Positive predictive value ${ }^{c}$} \\
\hline Study I & 91.3 & 70.8 \\
\hline Study 2 & 100 & 60.0 \\
\hline Total & 93.5 & 64.8 \\
\hline \multicolumn{3}{|c|}{ Negative predictive value $^{d}$} \\
\hline Study I & 46.7 & 66.7 \\
\hline Study 2 & 83.3 & 80.0 \\
\hline Total & 57.1 & 75.0 \\
\hline
\end{tabular}

${ }^{a}$ Sensitivity $=$ percentage of responders who were predicted to be responders. ${ }^{\mathrm{b}} \mathrm{Specificity}=$ percentage of nonresponders who were predictive to be nonresponders.

${ }^{\mathrm{C}}$ Positive predictive value $=$ response rate for patients who were predicted to be responders.

${ }^{\mathrm{d}}$ Negative predictive value $=$ nonresponse rate for patients who were predicted to be nonresponders.

placebo. Only one of nine women with a left-hemisphere advantage above the normal mean responded to 6 weeks of placebo (ie a response rate of $11 \%$ ), which is significantly smaller than the $94 \%$ response rate to fluoxetine for women who had above normal left-hemisphere advantage $\left(\chi^{2}=25.27, \mathrm{df}=1, p<0.001\right)$. In contrast, the $43 \%$ response rate to fluoxetine for women with a left-hemisphere advantage below the normal mean is not significantly different from the $33 \%$ response rate to placebo (ie three of nine) for women having below normal left-hemisphere advantage.

The PA scores for women on the dichotic fused-words and complex tones tests were also examined as combined and individual predictors of fluoxetine response in hierarchical logistic regression equations. The two asymmetry scores significantly improved prediction of treatment outcome over a constant alone $\left(\chi^{2}=13.75, \mathrm{df}=1, p<0.001\right)$. Asymmetry for the fused-words test was a significant predictor of treatment outcome on its own (Wald test $=8.67, \mathrm{df}=1, p<0.005)$, but the tone test did not contribute significant additional prediction over the asymmetry for the words test. The magnitude of left-hemisphere advantage for words among women was also found to predict the reduction in symptom severity on the HAM- $\mathrm{D}_{21}$ following 12 weeks of fluoxetine treatment. HAM- $\mathrm{D}_{21}$ ratings at baseline were not significantly related to PA 
scores for either words or tones. Controlling for baseline $\mathrm{HAM}-\mathrm{D}_{21}$ ratings, the change in ratings following 12 weeks of treatment was significantly correlated with baseline PA scores for words $(r=-0.32, p<0.05)$, but not tones $(r=-0.04$, NS). Thus, women with larger left-hemisphere advantage for words at baseline showed least severe symptoms after 12 weeks of treatment.

The right portion of Figure 3 shows the distribution of PA scores for men on the complex tone test, which significantly discriminated between responders and nonresponders. Men who responded to fluoxetine showed essentially no asymmetry (ie a mean PA score close to zero), whereas nonresponders tended to show the expected right-hemisphere advantage for tones. The mean PA score for healthy men (arrow labeled HM in Figure 3) was used as a cutoff score for dividing male patients into those with a PA score above $v s$ below the normal mean for tones. Patients with a PA score above the normal mean had a $65 \%$ response rate (ie 35 of 54 of these men were responders), whereas patients with a PA below the normal mean had only a $25 \%$ response rate (ie two of eight of these men were responders) to fluoxetine $\left(\chi^{2}=4.59, \mathrm{df}=1, p<0.05\right)$. Using this cutoff score to predict fluoxetine response among men, the complex tone test had high sensitivity but low specificity (Table 3), which is due to the mean PA score for healthy men being low (ie more negative) relative to the distribution of scores for patients (see right portion of Figure 3). The positive and negative predictive values were, however, moderately high for predicting response to fluoxetine among men.

Men with a PA score for complex tones above the normal mean had a higher response rate on fluoxetine than would be expected on placebo. Only nine or 39 men who had a PA score above the normal mean responded to 6 weeks of placebo (ie a response rate of $23 \%$ ), which is significantly smaller than the $65 \%$ response rate to fluoxetine in men who had a PA score above the normal mean $\left(\chi^{2}=15.86\right.$, $\mathrm{df}=1, p<0.001)$. Although sample sizes are small, men with a PA score below the normal mean did not differ in response rate on fluoxetine (25\%; two of eight were responders) as compared to placebo (29\%; two of seven were responders).

The PA scores for men on the fused-words and complex tones tests were also examined as combined and individual predictors of fluoxetine response in hierarchical logistic regression equations. The two asymmetry scores significantly improved prediction of treatment outcome over a constant alone $\left(\chi^{2}=4.85, \mathrm{df}=1, p<0.05\right)$. Asymmetry scores for men on the complex tone test was a significant predictor of treatment outcome on its own (Wald test $=4.06, \mathrm{df}=1, p<0.05)$, but the words test did not contribute significant additional prediction over the asymmetry for the tone test. The right-hemisphere advantage for complex tones among men was also found to predict the change in symptom severity on the HAM- $\mathrm{D}_{21}$ following 12 weeks of fluoxetine treatment. When controlling for baseline $\mathrm{HAM}-\mathrm{D}_{21}$ ratings, the change in ratings after 12 weeks of treatment was correlated with baseline PA scores for tones $(r=-0.43, p=0.001)$, but not for words $(r=0.05$, NS). Thus, men with little or no right-hemisphere advantage for tones (ie less negative or a positive PA score) showed the least severe symptoms after 12 weeks of treatment.

\section{DISCUSSION}

Differences among depressed patients in hemispheric asymmetry of function, as measured by dichotic listening tests, are predictive of therapeutic response to the SSRI fluoxetine. Patients who respond to fluoxetine differed from nonresponders in favoring left- over right-hemisphere processing of dichotic stimuli. Fluoxetine responders had overall greater left-hemisphere advantage for words and less right-hemisphere advantage for complex tones when compared to nonresponders. This was the case in two separate studies, one with patients having an MDD and the other with patients having a mixture of affective disorders, including MDD, dysthymia, or depression not otherwise specified. The consistency of findings across these studies and our prior study (Bruder et al, 1996) indicates that the difference in hemispheric asymmetry between fluoxetine responders and nonresponders is robust and replicable.

The difference in hemispheric asymmetry between fluoxetine responders and nonresponders was dependent on gender. Although women and men who responded to fluoxetine exhibited the same direction of asymmetry, favoring of left- over right-hemisphere processing, it was manifested on the verbal test in women but on the nonverbal test in men. Thus, the tendency for responders to have heightened left-hemisphere advantage for words was evident among women but not men, whereas the tendency for responders to have reduced or no righthemisphere advantage for tones was evident among men but not women. The abnormally large left-hemisphere advantage for words in women who responded to fluoxetine is the predominant PA seen among depressed adults and adolescents on the fused-words test (Pine et al, 2000; Bruder et al, 2004). In contrast, women who failed to respond to fluoxetine had a relatively small left-hemisphere advantage for words that did not differ significantly from healthy women. In men, differences between responders and nonresponders on the complex tone test were less marked than seen for women on the fused-words test. While depressed men who responded to fluoxetine had little or no right-hemisphere advantage for complex tones, nonresponders showed a right-hemisphere advantage that did not differ significantly from healthy men. Thus, the women and men who respond to fluoxetine show abnormal hemispheric asymmetries, which are not seen in nonresponders.

What might account for the finding of responder $v s$ nonresponder differences on the verbal test in women, but the nonverbal test in men? Heller (1993) speculated on the relation of gender differences in cognitive function and hemispheric organization to gender differences in depression. A maturational advantage of the left hemisphere among girls and right hemisphere among boys may lead to the development of tendencies for women to favor verbal strategies and men to favor nonverbal strategies. Women may therefore be more likely to ruminate when depressed, which would involve increased activation of left frontotemporal regions involved in verbal processing. One form of depression among women, which responds to an SSRI antidepressant, may be characterized by relatively greater activation of these left-hemisphere regions. The reduced right-hemisphere advantage for nonverbal dichotic listening in men who responded to fluoxetine agrees with that 
generally reported for depressed adults (Bruder et al, 1989; Overby et al, 1989), but this abnormality does appear to be more evident in depressed men than women (Bruder et al, 2004). The absolute accuracy data for the complex tone dichotic test indicate that the reduced right-hemisphere advantage in men who responded to fluoxetine was due to their better than normal performance for right-ear tones. Given the predominantly contralateral projections from ear to auditory cortex, this finding is more suggestive of lefthemisphere hyperactivation than right-hemisphere dysfunction. Thus, the findings for both men and women support the hypothesis that heightened left-hemisphere processing of dichotic stimuli is associated with favorable response to fluoxetine.

An important question that needs further study is why individual differences in hemispheric asymmetry among depressed patients are related to therapeutic responsiveness to an SSRI antidepressant? One possible reason is that the serotonin neurotransmitter system implicated in depressive disorders and affected by SSRI antidepressants may have a lateralized distribution in the brain or may be asymmetrically disrupted in a subtype of depression that responds to an SSRI. Although it has been suggested that the serotonin neurotransmitter system is asymmetrically distributed in the brain (Mandell and Knapp, 1979; Tucker and Williamson, 1984), the findings of postmortem studies have been inconsistent (Arato et al, 1991a; Arora and Meltzer, 1991). Neuroimaging studies have provided evidence that individual differences among depressed patients in regional brain activity are related to subsequent response to an SSRI or other antidepressants (Buchsbaum et al, 1997; Mayberg et al, 1997; Brody et al, 1999; Hoehn-Saric et al, 2001; Saxena et al, 2003; Davidson et al, 2003). Relatively greater activity of the left rectal gyrus (Buchsbaum et al, 1997), anterior cingulate (Davidson et al, 2003), or prefrontal regions (Hoehn-Saric et al, 2001) was reported to be predictive of favorable response to antidepressants. Although the relation of these neuroimaging findings to our dichotic listening findings is unclear, they do raise the intriguing possibility that the favoring of left-hemisphere processing of dichotic stimuli in fluoxetine responders may reflect relatively greater left-sided activation in these regions.

The responder $v s$ nonresponder dichotomy has proven useful for demonstrating the relation of pretreatment differences in brain function and therapeutic responsiveness to antidepressants. Moreover, patients who respond to a specific antidepressant, in this case the SSRI fluoxetine, are likely to be more homogeneous in their etiology and biological characteristics. Thus, SSRI responders may have an abnormality of the serotonergic neurotransmitter system that is not shared by patients who do not respond to an SSRI. Our current findings and those of prior studies support the existence of treatment-responsive and -nonresponsive subtypes of depression that differ in functional brain asymmetry (Bruder et al, 1990, 1996; Stewart et al, 1999).

Our findings also suggest the possible clinical value of dichotic listening tests for predicting therapeutic response to an SSRI. The potential value of dichotic listening tests, as opposed to electrophysiologic or neuroimaging tests, is that they are easy and inexpensive to administer in an office or clinical setting. The dichotic fused-words test (Wexler and Halwes, 1983) shows particular promise as a clinical aid for identifying depressed women who are likely to benefit from treatment with the SSRI fluoxetine. Women with above normal left-hemisphere advantage on the fused-words test had a $94 \%$ response rate to fluoxetine, but only an $11 \%$ response rate to placebo. In addition to its high sensitivity and positive predictive value, the fused-words test also demonstrated its value for identifying women who are not likely to benefit from treatment with fluoxetine. Among women who received dichotic tests, $27 \%$ failed to respond to fluoxetine and another $22 \%$ responded to placebo. This suggests that up to half of the women should not have been treated with fluoxetine. If instead of treating all women with fluoxetine we applied the fused-words test and gave fluoxetine only to those with above normal left-hemisphere advantage, only $6 \%$ would fail to respond to fluoxetine and their expected placebo response rate would be $11 \%$. Thus, the number of women who would be unnecessarily treated with this SSRI would be reduced from 49 to $17 \%$. Moreover, in those women with below normal left-hemisphere advantage for words, the response rate to fluoxetine (43\%) is not likely to be any better than to placebo (33\%). The potential value of the fused-words test for identifying women who are unlikely to respond to fluoxetine is important because they may become increasingly hopeless when they fail to benefit from this SSRI and drop out before receiving an appropriate alternative treatment.

Although differences between responders and nonresponders were less marked for men, those with less than normal right-hemisphere advantage on the complex tones test were more than twice as likely to respond to fluoxetine than men who had a greater than normal right-hemisphere advantage. The complex tone test had excellent sensitivity for predicting treatment response in men, but its predictive value is weakened by low specificity. Pretreatment dichotic listening performance was predictive of the change in severity of depressive symptoms following fluoxetine treatment. Men with less right-hemisphere advantage for tones and women with greater left-hemisphere advantage for words had the least severe symptoms after 12 weeks of treatment. Further study of the value of dichotic listening tests in clinic settings should be performed to demonstrate prospectively its utility as an aid for selecting treatments that will most benefit individual patients.

Lastly, there are several limitations or questions that should be discussed. First, a higher proportion of nonresponders than responders had a comorbid anxiety disorder. This is not unexpected given findings of poorer treatment outcome in depressed patients having a comorbid anxiety disorder (Fava et al, 1997; Frank et al, 2000). The comorbidity difference is not likely to be a critical factor because the difference in asymmetry between responders and nonresponders remained the same when patients having comorbidity were excluded from analyses. Second, one could question whether the gender differences in dichotic listening for responders and nonresponders might be related to the fewer men than women with an MDD. There was, however, no difference between responders and nonresponders in MDD diagnoses. Also, all men and women in Study 1 met criteria for MDD, and gender differences for responders and nonresponders were the 
same as seen for the full samples. Third, a question could be raised as to whether our findings reflect response to fluoxetine or a nonspecific placebo response? In Study 2, only patients who did not respond to 6 weeks of placebo received treatment with fluoxetine. Although the sample of placebo responders in that study was relatively small, they did not show differences in dichotic listening when compared to placebo nonresponders. Moreover, patients with PA scores above the normal mean, who were predicted to respond to fluoxetine, had a response rate on fluoxetine that was considerably greater than the response rate on placebo. Thus, it is unlikely that the findings for fluoxetine responders reflect a nonspecific placebo response. Lastly, dichotic listening tests yield only limited information concerning relative differences in hemispheric asymmetry. Future studies should also use electrophysiologic or neuroimaging measures to provide more direct measures of regional hemispheric activation in treatment-responsive and -nonresponsive subgroups.

\section{ACKNOWLEDGEMENTS}

This research was supported in part by National Institute of Mental Health Grants MH36295 and MH56058. We thank Donald F Klein for his helpful comments on a prior draft of this manuscript, and Pual Leite, Barbara Stuart, Mia Sage, and Carlye Griggs for their help with data collection and processing.

\section{REFERENCES}

Arato M, Frescksa E, MacGrimmon DJ, Guscott R, Saxena B, Tekes $\mathrm{K}$ et al (1991a). Serotonergic interhemispheric asymmetry: neurochemical and pharmaco-EEG evidence. Prog Neuropsychopharmacol Biol Psychiatry 15: 759-764.

Arato M, Frecska E, Tekes K, MacCrimmon DJ (1991b). Serotonergic interhemispheric asymmetry: gender difference in the orbital cortex. Acta Psychiatr Scand 84: 110-111.

Arora RC, Meltzer HY (1991). Laterality and ${ }^{3} \mathrm{H}$-imipramine binding: studies in the frontal cortex of normal controls and suicide victims. Biol Psychiatry 29: 1016-1022.

Brody AL, Saxena S, Silverman DHS, Alborzian S, Fairbanks LA, Phelps ME et al (1999). Brain metabolic changes in major depressive disorder from pre- to post-treatment with paroxetine. Psychiatry Res Neuroimag 91: 127-139.

Bruder G (2003). Frontal and parietotemporal asymmetries in depressive disorders: behavioral, electrophysiologic, and neuroimaging findings. In: Hugdahl $\mathrm{K}$, Davidson $\mathrm{RH}$ (eds). The Asymmetrical Brain. MIT Press: Cambridge, MA. pp 719-742.

Bruder GE (1988). Dichotic listening in psychiatric patients. In: Hugdahl K (ed). Handbook of Dichotic Listening: Theory, Methods and Research. Wiley: New York, NY. pp 661-691.

Bruder GE, Otto MW, Stewart JW, McGrath P, Fava M, Rosenbaum JF et al (1996). Dichotic listening before and after fluoxetine treatment for major depression: relations of laterality to therapeutic response. Neuropsychopharmacology 15: 171-179.

Bruder GE, Quitkin FM, Stewart JW, Martin C, Voglmaier M, Harrison WM (1989). Cerebral laterality and depression: differences in perceptual asymmetry among diagnostic subtypes. J Abnorm Psychol 98: 177-1986.

Bruder GE, Schneier FR, Stewart JW, McGrath PJ, Quitkin F (2004). Left hemisphere dysfunction during verbal dichotic listening tests in patients who have social phobia with or without comorbid depressive disorder. Am J Psychiatry 161: 72-78.
Bruder GE, Stewart JW, Tenke CE, McGrath PJ, Leite P, Bhattacharya $\mathrm{N}$ et al (2001). Electroencephalographic and perceptual asymmetry differences between responders and nonresponders to an SSRI antidepressant. Biol Psychiatry 48: 416-425.

Bruder GE, Stewart JW, Voglmaier MM, Harrison WM, McGrath P, Tricamoo E et al (1990). Cerebral laterality and depression: relations of perceptual asymmetry to outcome of treatment with tricyclic antidepressants. Neuropsychopharmcology 3: 1-10.

Bryden MP (1988). An overview of the dichotic listening procedure and its relation to cerebral organization. In: Hugdahl K (ed). Handbook of Dichotic Listening: Theory, Methods and Research. Wiley: Chichester, UK. pp 1-43.

Buchsbaum MS, Wu J, Siegel BV, Hackett E, Trenary M, Abel L et al (1997). Effect of sertraline on regional metabolic rate in patients with affective disorder. Biol Psychiatry 41: 15-22.

Cook IA, Leuchter AF (2001). Prefrontal changes and treatment response prediction in depression. Semin Clin Neuropsychiatry 6: $113-120$.

Davidson RJ, Irwin W, Anderle MJ, Kalin NH (2003). The neural substrates of affective processing in depressed patients treated with venlafaxine. Am J Psychiatry 160: 64-75.

Dunkin JJ, Leuchter AF, Cook IA, Kasi-Godey JE, Abrams M, Rosenberg-Thompson S (2000). Executive dysfunction predicts nonresponse to fluoxetine in major depression. J Affect Disord 60: $13-23$.

Fava M, Uebelacker LA, Alpert JE, Nierenberg AA, Pava JA, Rosenbaum JF (1997). Major depressive subtypes and treatment response. Biol Psychiatry 42: 568-576.

Figueras G, Perez V, San Martino O, Alvarez E, de Trastornos Afectivos G, Artigas F (1999). Pretreatment platelet 5-HT concentration predicts the short-term response to paroxetine in major depression. Biol Psychiatry 46: 518-524.

Frank E, Shear MK, Rucci P, Cyranoswki JM, Endicott J, Fagiolini $A$ et al (2000). Influence of panic-agroraphobic spectrum symptoms on treatment response in patients with recurrent major depression. Am J Psychiatry 157: 1101-1107.

Gur RC, Alsop D, Glahn D, Petty R, Swanson CL, Maldjian JA et al (2000). An fMRI study of sex differences in regional activation to a verbal and a spatial task. Brain Lang 74: 157-170.

Heller W (1993). Gender differences in depression: perspectives from neuropsychology. J Affect Disord 29: 129-143.

Hiscock M, Israelian M, Inch R, Jacek C, Hiscock-Kalil C (1995). Is there a sex difference in hum laterality? II. An exhaustive survey of visual laterality studies from six neuropsychology journals. J Clin Exp Neuropsychol 17: 590-610.

Hoehn-Saric R, Schlaepfer TE, Greenberg BD, McLeod DR, Pearlson GD, Wong SH (2001). Cerebral blood flow in obsessive-compulsive patients with major depression: effect of treatment with sertraline or desipramine on treatment responders and non-responders. Psychiatry Res Neuroimag 108: 89-100.

Hugdahl K, Rund BR, Lund A, Asbjørnsen A, Egeland J, Landrø NI et al (2003). Attentional and executive dysfunctions in schizophrenia and depression: evidence from dichotic listening performance. Biol Psychiatry 53: 609-616.

Joyce PR, Paykel ES (1989). Predictors of drug response in depression. Arch Gen Psychiatry 46: 89-99.

Kalayam B, Alexopoulos GS (2003). A preliminary study of left frontal region error negativity and symptom improvement in geriatric depression. Am J Psychiatry 160: 2054-2056.

Kansaku K, Yamaura A, Kitazawa S (2000). Sex differences in lateralization revealed in the posterior language areas. Cerebr Cortex 10: 866-872.

Kimura D (1999). Sex and Cognition. MIT Press: London.

Mandell AJ, Knapp S (1979). Asymmetry and mood, emergent properties of serotonin regulation. Arch Gen Psychiatry 36: 909-916. 
Mayberg HS, Brannan SK, Mahurin RK, Jerabek PA, Brickman JS, Tekell JL et al (1997). No effect of depression on [ $\left.{ }^{15} \mathrm{O}\right] \mathrm{H}_{2} \mathrm{O}$ PET response to intravenous $d$-fenfluramine. Am J Psychiatry 155: 1241-1246.

McGlone J (1980). Sex differences in human brain asymmetry: a critical survey. Behav Brain Sci 3: 215-263.

Mulert C, Juckel G, Augustin H, Hegerl U (2002). Comparison between the analysis of the loudness dependency of the auditory N1/P2 component with LORETA and dipole source analysis in the prediction of treatment response to the selective serotonin reuptake inhibitor citalopram in major depression. Clin Neurophysiol 113: 1566-1572.

Oldfield RC (1971). The assessment and analysis of handedness: the Edinburgh inventory. Neuropsychologia 9: 97-113.

Overby III LA, Harris AE, Leck MR (1989). Perceptual asymmetry in schizophrenia and affective disorder: implications from a right hemisphere task. Neuropsychologia 27: 861-870.

Pine D, Kentgen LM, Bruder GE, Leite P, Bearman K, Ma Y et al (2000). Cerebral laterality in adolescent major depression. Psychiatry Res 93: 135-144.

Pizzagalli D, Pascual-Marqui RD, Nitschke JB, Oakes TR, Larson $\mathrm{CL}, \mathrm{Abercrombie} \mathrm{HC}$ et al (2001). Anterior cingulate activity as a predictor of degree of treatment response in major depression: evidence from brain electrical tomography analysis. $A m \mathrm{~J}$ Psychiatry 158: 405-415.

Saxena S, Brody AL, Ho ML, Zohrabi N, Maidment KM, Baxter LR (2003). Differential brain metabolic predictors of response to paroxetine in obsessive-compulsive disorder versus major depression. Am J Psychiatry 160: 522-532.

Shaywitz BA, Shaywitz SE, Pugh KR, Constable RT, Skudlarski P, Fulbright RK et al (1995). Sex differences in the functional organization of the brain for language. Nature 373: 607-609.
Sidtis JJ (1981). The complex tone test: implications for the assessment of auditory laterality effects. Neuropsychologia 19: 103-112.

Sotsky SM, Glass D, Shea MT, Pilkonis PA, Collins JF, Elkin I et al (1991). Patient predictors of response to psychotherapy and pharmacotherapy: findings in the NIMH treatment of depression collaborative research program. Am J Psychiatry 148: 997-1008.

Steiner M, Lepage P, Dunn EJ (1997). Serotonin and genderspecific psychiatric disorders. Int J Psychiatry Clin Pract 1: 3-13.

Stewart JW, Quitkin FM, McGrath PJ, Bruder GE (1999). Do tricyclic responders have different brain laterality? J Abnorm Psychol 108: 707-710.

Tucker DM, Williamson PA (1984). Asymmetric neural control system in human self-regulation. Psychol Bull 91: 185-215.

Weissman MM, Leaf PJ, Holzer III CE, Myers JK, Tischler GL (1984). The epidemiology of depression: an update on sex differences in rates. J Affect Disord 7: 179-188.

Wexler BE, Halwes T (1983). Increasing the power of dichotic methods. The fused rhymed words test. Neuropsychologia 21: 59-66.

Wexler BE, Mason JW, Giller EL (1989). Possible subtypes of affective disorders suggested by differences in cerebral laterality and testosterone: a preliminary report. Arch Gen Psychiatry 6: 278-288.

Zanardi R, Serrett A, Rossini D, Franchini L, Cusin C, Lattuada E et al (2001). Factors affecting fluvoxamine antidepressant activity: influence of pinodolol and 5-HTTLPR in delusional and nondelusional depression. Biol Psychiatry 50: 323-330.

Zatorre RJ (1989). Perceptual asymmetry on the dichotic fused words test and cerebral speech lateralization determined by the carotid sodium amytal test. Neuropsychologia 27: 1207-1219. 